\title{
Comparison of the thick smear and Kato-Katz techniques for diagnosis of intestinal helminth infections
}

\author{
Comparação das técnicas de sedimentação espontânea e Kato-Katz \\ para diagnóstico das helmintoses intestinais
}

\author{
Fred Luciano Neves Santos ${ }^{1}$, Elúzio José Lima Cerqueira ${ }^{1}$ and Neci Matos Soares ${ }^{1}$
}

\begin{abstract}
This study compared the efficiency of Kato-Katz thick smear and thick smear techniques for the diagnosis of intestinal helminths. The sensitivity of the thick smear technique was higher than that of the Kato-Katz method for the diagnosis of all helminths except Schistosoma mansoni.
\end{abstract}

Key-words: Kato-Katz. Direct examination. Sensitivity. Specificity. Prevalence.

\section{RESUM0}

O objetivo deste trabalho foi comparar a eficiência dos métodos de Kato-Katz e sedimentação espontânea para 0 diagnóstico das helmintíases intestinais. A sensibilidade da técnica de sedimentação espontânea foi superior aquela encontrada pelo método de Kato-Katz para o diagnóstico de todos os helmintos, exceto para Schistosoma mansoni.

Palavras-chaves: Kato-Katz. Sedimentação espontânea. Sensibilidade. Especificidade. Prevalência.

In 1954, Kato and Miura introduced a thick-smear technique for fecal examination ${ }^{3}$. Soon thereafter, Katz modified and adapted this technique for use in field studies. This method was adopted by $\mathrm{WHO}^{8}$ for quantitative and qualitative diagnosis of intestinal infections caused by helminths such as Ascaris lumbricoides, Trichuris trichiura, hookworm and Schistosoma mansoni, and has also been used in laboratory diagnosis ${ }^{8}$. Although the Kato-Katz method is widely used for the diagnosis of intestinal helminths infections, its reported effectiveness varies. Garcia et $\mathrm{al}^{2}$ observed that the Kato-Katz method was more sensitive than the thick smear technique for diagnosing helminths ${ }^{2}$, while Martin \& Beaver ${ }^{5}$ concluded that the Kato thick-smear technique is reliable and practical for the quantitative diagnosis of hookworm, Trichuris Trichiura and Schistosomeinfections ${ }^{5}$. On the other hand, Engels etal ${ }^{1}$ showed that the Kato-Katz method is not suitable for hookworm, protozoa and filariform larvae detection ${ }^{1}$; while another study concluded that the Kato method has a low sensitivity for identifying hookworm eggs, and observed that hookworm eggs collapsed and disappeared shortly after the thick smear had cleared ${ }^{9}$. Here, we present a comparative study of the Kato-Katz and thick smear methods for detection of Ascaris lumbricoides, T. trichiura, hookworm and S. mansoni.

This study was based on 258 stool samples collected from school-children, aged 6-14 years, from Salinas da Margarida County Public School (Bahia State), from January to June 2001. All samples were examined by the quantitative Kato-Katz and the qualitative thick smear methods, according to standardized procedures described elsewhere ${ }^{6}$. Three slides were prepared per person, and egg-counts from Kato-Katz slides were conducted 24 hours after its preparation. The sensitivity and specificity of each method in isolation and of the two methods together were calculated using Epi-info (version 6) software. The kappa statistic ${ }^{15}$ was used to assess the concordance of test results obtained with the two individual techniques, and McNemar's test for paired proportions was used to compare the prevalences obtained with each of the individual methods, according to the normal theory test?

Overall, $89.1 \%$ of samples were positive for cysts of protozoa (data not shown) and/or helminth eggs (Table 1). Thick smear identified a larger fraction of patients infected

\footnotetext{
1. Laboratório de Parasitologia Clínica da Faculdade de Farmácia da Universidade Federal da Bahia, Salvador, BA. This work was supported by the Fundação de Apoio a Pesquisa do Estado da Bahia (FAPESB). Brazil.

Address to: Dr. Fred Luciano Neves Santos. Lab. de Parasitologia Clínica/FF/UFBA. Av. Barão de Geremoabo, s/n. 41170-280 Salvador, BA. Fax: 5571 237-2255.

e-mail: neci@ufba.br

Recebido para publicação em 28/10/2003

Aceito em 15/12/2005
} 
with helminths. The difference was most evident for hookworm, where the ratio of positive samples identified by thick smear and Kato-Katz was 73:1. However, combined examination with the thick smear and Kato-Katz techniques gave better results than when the thick-smear was used alone (Table 1). Compared to thick smear, the sensitivity of the Kato-Katz method was $68.2 \%$ for T. trichiura, $70.8 \%$ for A. lumbricoides and 1.4\% for hookworm, and the specificity was $60.2 \%$ for T. trichiura, $84.1 \%$ for A lumbricoides, and 100\% for hookworm (Table 2). However, the infections detected with these different techniques were not necessarily the same, which means that even the sensitivity of these improved individual techniques is far from ideal, and health personnel should be aware that a person is not
Table 1 - Prevalence of common intestinal parasites detected by different techniques of faeccal examination in 258 children from a public school in Salinas da Margarida, County, Bahia.

\begin{tabular}{cccc}
\hline \multirow{3}{*}{ Parasite } & \multicolumn{3}{c}{ Prevalence (\%) } \\
\cline { 2 - 4 } & Thick smear & Kato-Katz & Thick smear + \\
& Method & technique & Kato-Katz techniques \\
\hline
\end{tabular}

\section{Helminthes,}

Eggs/larvae

T. trichiura

A lumbricoides

$170(66.0 \%)$

$131(58.5 \%)$

$205(79.5 \%)$

Hookworms

$107(41.5 \%)$

$142(55.0 \%)$

S. stercoralis $\quad 4(1.5 \%)$

$1(0.4 \%)$

$73(28.3 \%)$

S. stercoralis $\quad 4(1.5 \%)$

$4(1.5 \%)$

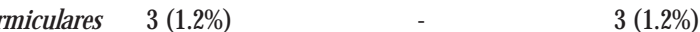

$\begin{array}{lll}\text { S. mansoni } & 1(0.4 \%) & 2(0.8 \%)\end{array}$

\begin{tabular}{|c|c|c|c|c|c|c|}
\hline & \multirow[b]{2}{*}{ Kato-Katz } & \multicolumn{2}{|c|}{ Thick smear } & \multirow[b]{2}{*}{$\begin{array}{l}\text { sensitivity } \\
(\%)(\mathrm{CI})\end{array}$} & \multirow[b]{2}{*}{$\begin{array}{l}\text { specificity } \\
(\%)(C I)\end{array}$} & \multirow[b]{2}{*}{$\begin{array}{l}\text { Kappa Index } \\
\text { (CI) }\end{array}$} \\
\hline & & positive & negative & & & \\
\hline \multirow[t]{2}{*}{ T. trichiura } & positive & 116 & 35 & $\begin{array}{c}68.2 \\
(61.2-75.2)\end{array}$ & $\begin{array}{c}60.2 \\
(50.0-70.5)\end{array}$ & $\begin{array}{c}0.27 \\
(0.15-0.39)\end{array}$ \\
\hline & negative & 54 & 53 & & & \\
\hline \multirow[t]{2}{*}{ A lumbricoides } & positive & 85 & 22 & $\begin{array}{c}70.8 \\
(62.7-79.0)\end{array}$ & $\begin{array}{c}84.1 \\
(78.0-90.2)\end{array}$ & $\begin{array}{c}0.55 \\
(0.45-0.66)\end{array}$ \\
\hline & negative & 35 & 116 & & & \\
\hline \multirow[t]{2}{*}{ Hookworm } & positive & 1 & 0 & $\begin{array}{c}1.4 \\
(-.1 .3-4.0)\end{array}$ & 100 & $\begin{array}{c}0.02 \\
(-0.17-0.21)\end{array}$ \\
\hline & Negative & 72 & 185 & & & \\
\hline \multirow[t]{2}{*}{ S. mansoni } & positive & 1 & 1 & 100 & $\begin{array}{c}99.6 \\
(98.8-100.4)\end{array}$ & $\begin{array}{c}0.66 \\
(0.01-1.32)\end{array}$ \\
\hline & negative & 0 & 256 & & & \\
\hline
\end{tabular}

to be classified as uninfected on the basis of a simple negative examination by one of these techniques conducted in isolation. The Kappa statistic indicated that agreement between the Kato and thick smear methods was good for A lumbricoides $(\kappa=0.55)$, and marginal for T. trichiura $(\kappa=0.27)$ and hookworm $(\kappa=0.02)$. In addition, McNemar's test indicated that direct examination was more likely to correctly identify $\mathrm{T}$. trichiura than the Kato-Katz method $\left(\chi^{2}=3.64, p=0.056\right)$, although the prevalences of A lumbricoideswere notsignificantlydifferent $\left(\chi^{2}=2.526, p=0.11\right)$.

However, comparison of the individual methods with the McNemar testindicated that directexamination was more reliable for determining infection with $\mathrm{T}$. trichiura. Larger sample sizes would be necessary for determining whether the directexamination is also more reliable for detecting A. lumbricoides.

The present study found that the Kato-Katz method were less sensitive than thick smear for detecting hookworm infections. Previous reports ${ }^{19}$ have suggested that Kato-Katz could be adequate for detecting hookworm. However, these studies only examined a single slide per patient, and the Kato-Katz slides were read immediately after preparation. It is likely that hookworm eggs deteriorate during the standardized 24-hour period before slide reading, which would explain the low prevalences identified by Kato-Katz in this study. Nevertheless, we concluded that the Kato-Katz method, when used with the thick smear, would be particularly appropriate for large-scale surveys because of its simplicity, lower cost, and rapidity.

\section{ACKNOWLEDGEMENTS}

To Craig Andrews Milroy for his help with the critical review of the manuscript and for statistical analysis.

\section{REFERENCES}

1. Engels D, Nahimana S, Gryseels B. Comparison of the direct faecal smear and two thick smear techniques for the diagnosis of intestinal parasitic infections. Transactions of the Royal Society of Tropical Medicine and Hygiene 90: 523-25, 1996.

2. Garcia JA, Martin AM, Perez MJ. Valoración de los métodos utilizados en el diagnóstico de parasitosis intestinales. Laboratório 79: 473, 1985.

3. Kato K, Miura M. Comparative examinations. Japanese Journal of Parasitology 3: 35, 1954.

4. Katz N, Chavez A, Pellegrino J. A simple device for quantitative stool thicksmear technique in schistosomiasis mansoni. Revista do Instituto de Medicina Tropical de São Paulo 14: 397-400, 1972.

5. Martin LK, Beaver PC. Evaluation of Kato thick-smear technique for quantitative diagnosis of helminth infections. The American Journal of Tropical Medicine and Hygiene 17: 382-391, 1968. 
6. Rocha MO. Exame Parasitológico de Fezes. In: Neves DP (ed) Parasitologia Humana, 10 $0^{\text {th }}$ editition, Atheneu, São Paulo, p. 403-411, 2000.

7. Rosner B. Hypothesis testing: categorical data. In: Fundamentals of Biostatistics, $4^{\text {th }}$ edition, Wadsworth Publishing Co. p. 345-442, 1995.

8. World Health Organization. Cellophane faecal thick smear examination technique (Kato) for diagnosis of intestinal schistosomiasis and gastrointestinal helminth infections. PDP 83: 3, 1993.
9. Zamen V, Cheong CH. A comparison of Kato thick smear technique with zinc sulfate flotation method, for the detection of helminth ova in faeces. Transactions of the Royal Society of Tropical Medicine and Hygiene 61: 751, 1967. 